\title{
The postnatal growth of the $\beta$-cell mass in pigs
}

\author{
T Bock $^{1,2}$, A Kyhnel ${ }^{2}$, B Pakkenberg ${ }^{2}$ and K Buschard ${ }^{1}$ \\ ${ }^{1} \mathrm{H}: \mathrm{S}$ The Bartholin Institute, Copenhagen University Hospital, DK-1399 Copenhagen K, Denmark \\ ${ }^{2}$ Research Laboratory for Stereology and Neuroscience, H:S Bispebjerg Hospital, Copenhagen University Hospital, Copenhagen, Denmark. \\ (Requests for offprints should be addressed to T Bock, H:S The Bartholin Institute, University Hospital of Copenhagen, Bartholinsgade 2, DK-1399 Copenhagen \\ K, Denmark; Email: tbock@post12.tele.dk)
}

\begin{abstract}
Studies of the postnatal growth of the $\beta$-cell mass in rats have revealed some unexpected and apparently paradoxical results, the most prominent being a $\beta$-cell mass plateau in the early phase of life. We have studied the postnatal growth of the $\beta$-cell mass in the domestic pig to investigate its development in a larger mammal. The pancreases from a total of 86 male pigs from 5 to 100 days of age were studied. The $\beta$-cell mass increased linearly from day 5 to day 40 , reached a plateau from day 40 to day 60 , and then increased further into adulthood. The relative $\beta$-cell mass ( $\beta$-cell mass per body mass) was increased in the early postnatal period but reached a constant level from day 60 , after which there was a linear relationship between the $\beta$-cell mass and the body mass. There were high rates of
\end{abstract}

both $\beta$-cell apoptosis and mitosis at 50 and 60 days of age, while the volume-weighted mean islet volume increased from birth and reached a plateau at approximately 60 days of age. A $\beta$-cell mass plateau early in life accompanied by a wave of $\beta$-cell apoptosis coinciding with the relative $\beta$-cell mass decreasing to reach a constant level, and a linear relationship between the $\beta$-cell mass and the body mass in later life is exactly what has previously been reported in rats. The coincidence of these events in both rats and pigs, although occurring at different ages in the two species, suggests a causal relationship as previously suggested in a proposed explanatory model for postnatal $\beta$-cell growth.

Journal of Endocrinology (2003) 179, 245-252

\section{Introduction}

The $\beta$-cell mass in rats, following a slow and apparently constant increase from postnatal day 4 to postnatal day 16 , reaches a plateau phase from day 16 until day 24 followed by a further increase into adulthood (Finegood et al. 1995, Scaglia et al. 1997, Svenstrup et al. 2002). This plateau phase seems to be paradoxical when the pronounced increase in whole body and organ weight in this time-interval is considered. We have previously reported that in rats the $\beta$-cell mass plateau phase coincides in time with the decrease in the relative $\beta$-cell mass ( $\beta$-cell mass per body mass), and that the $\beta$-cell mass plateau phase ends when the relative $\beta$-cell mass reaches a constant level that is maintained into and during adulthood (Svenstrup et al. 2002). We have suggested that these two events are causally related, and that the $\beta$-cell mass plateau is part of an adaptation from the $\beta$-cells to the high relative $\beta$-cell mass, implying an increased tendency for apoptosis. In the present study, we have investigated the postnatal growth of the $\beta$-cell mass in the domestic pig to explore whether the characteristics observed in rats could be reproduced in a larger mammal.

\section{Materials and Methods}

Pigs

All pigs were purchased from Sealand III (Roskilde, Denmark), which is a research plant owned and managed by The Danish Slaughteries, Copenhagen, Denmark. All breeder females were Danish-Landrace/DanishYorkshire while all breeder males were Danish-Duroc, a constellation commonly used in commercial pig breeding. The piglets were fed by their mothers until weaning at postnatal day 28 . From then they were fed a conventional diet as used in commercial pig breeding (Roskilde Andel AMBA, Roskilde, Denmark).

\section{Study groups}

A total of 86 male piglets at different ages were studied. Ages studied were postnatal day $5(n=5), 10(n=5), 15(n=8), 20$ $(n=6), 25(n=6), 30(n=6), 40(n=6), 50(n=9), 60(n=12)$, $70(n=6), 80(n=6), 90(n=5)$ and $100(n=6)$. Piglets from one litter were randomized into only one of the study groups, and no sow delivered more than three piglets into one age group. The piglets were killed by either a lethal injection of barbituric acid or by a bolt pistol followed by exsanguination depending on age. All such procedures were performed by authorized staff members according to Danish laws. The total pancreas was immediately removed, weighed and fixed in 10\% buffered formalin, $\mathrm{pH} 7 \cdot 4$.

\section{Histology}

Following fixation, the pancreas was embedded in 4\% agar to allow sectioning of the entire pancreas into $4 \mathrm{~mm}$ thick 

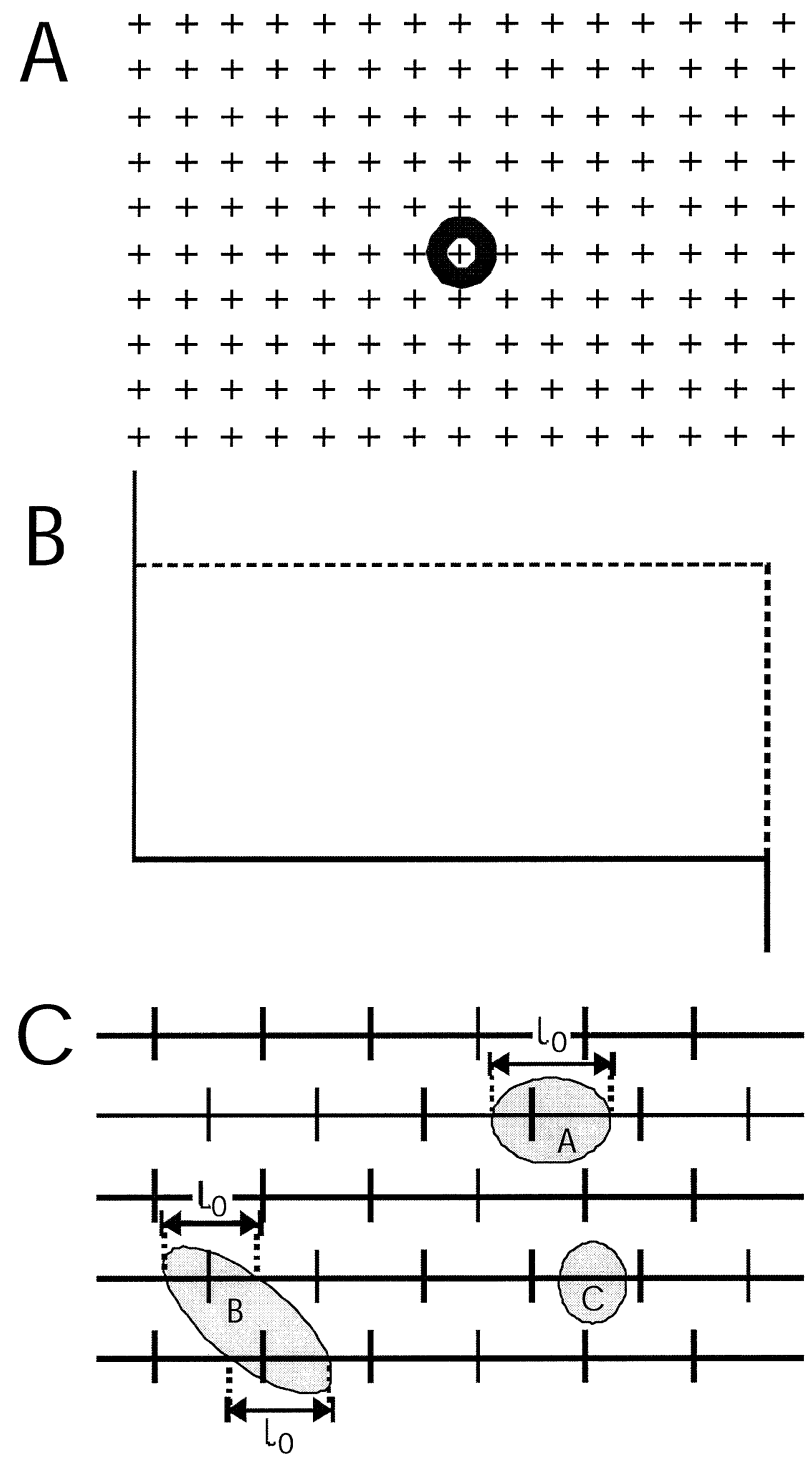

Figure 1 The different grids applied in the stereological investigations. (A) The point-counting grid applied for the determination of the volume-ratio of $\beta$-cells and pancreas. Using systematical uniformly random sampling at all levels we counted how many of the 150 points in the grid that hit $\beta$-cells and, in the same sampling session, how many times the encircled point (the unit-point) hits pancreatic or non-pancreatic tissue. (B) The sampling frame used to sample $\beta$-cell nuclei for determination of the fraction of $\beta$-cell mitosis and $\beta$-cell apoptosis. The rule of the sampling frame is that nuclei that are either completely within the frame or touch only the inclusion lines (the dashed lines) are defined as inside the frame, while nuclei completely outside the frame and nuclei that touch the exclusions lines (the solid lines) are defined as outside the frame. (C) The technique to determine the volume-weighted mean islet volume. Each time a point hits an islet the length of the horizontal intersect through the sampling point $\left(\mathrm{I}_{\mathrm{o}}\right)$ was measured. Three islet profiles (shaded areas) are shown. Islet A was hit by one point and, therefore, one intersect length was measured, islet $C$ was not hit by any points and no intersect was measured, while islet B was hit by two points and then two intersect lengths were recorded. slices. The first cut was placed at a random position between 0 and $4 \mathrm{~mm}$ in each pancreas to ensure systematic uniform random sampling (SURS) (Gundersen \& Jensen 1987). Between six and ten of the $4 \mathrm{~mm}$ thick slices were sampled according to SURS, each of these slides was embedded into paraffin, and one $3 \mu \mathrm{m}$ thick section was then cut from the top of each block. The $\beta$-cells were visualized by immunohistochemistry using a guinea pig anti-insulin antibody (Dako, Glostrup, Denmark; dilution 1:50) as primary antibody followed by Envision-AP (a polymer backbone to which alkaline phosphatase, goat anti-rabbit immunoglobulin antibody and goat anti-mouse immunoglobulin antibody are attached; Dako; dilution 1:1). Antibody binding was visualized by incubation with Fast Red (Sigma FAST fast red; Sigma, St Louis, MO, USA). Mayer's haematoxylin was used as counterstaining.

\section{Stereology}

The sections were examined using an Olympus BH-2 microscope equipped with a projecting arm to project the image onto the table (final magnification $\times 145$ ), and an automated $x-y$ stepper (Lang GMBH, Hüttenberg, Germany) to allow sampling of fields of vision according to SURS. Using a point-counting grid with 150 points (Fig. $1 \mathrm{~A}$, one of them encircled (the unit-point), the total number of points that hit $\beta$-cells and the number of unit-points that hit the pancreas, and the number of unit-points that hit non-pancreatic tissue such as fat or lymph nodes was counted on all sections from each pancreas. The $\beta$-cell mass and the pancreatic mass were then calculated according to:

$$
\begin{aligned}
& M(\beta)=M(\text { tis }) \times \frac{P(\beta)}{150 \times\left(P_{U}(\text { pan })+P_{U}(\text { non-pan })\right)} \\
& M(\text { pan })=M(\text { tis }) \times \frac{P_{U}(\text { pan })}{P_{U}(\text { pan })+P_{U}(\text { non-pan })}
\end{aligned}
$$

where $M(\beta)$ is the total $\beta$-cell mass, $M($ tis $)$ is the weight of the tissue removed from the abdomen of the pig, $\mathrm{P}(\beta)$ is the number of points that hit $\beta$-cells, $\mathrm{P}_{U}($ pan $)$ is the number of unit-points that hit pancreatic tissue, $\mathrm{P}_{\mathrm{U}}$ (nonpan) is the number of unit-points that hit non-pancreatic tissue, and $M($ pan) is the total mass of the pancreas.

\section{$\beta$-Cell mitosis and apoptosis}

From three randomly selected pigs in each of the age groups postnatal day $5,10,20,30,40,50,60,70,80,90$ and 100, two randomly selected sections among the sections stained for insulin as described above were used to determine the rate of $\beta$-cell mitosis and apoptosis. The sections were investigated systematically according to SURS with a counting frame attached to the table 

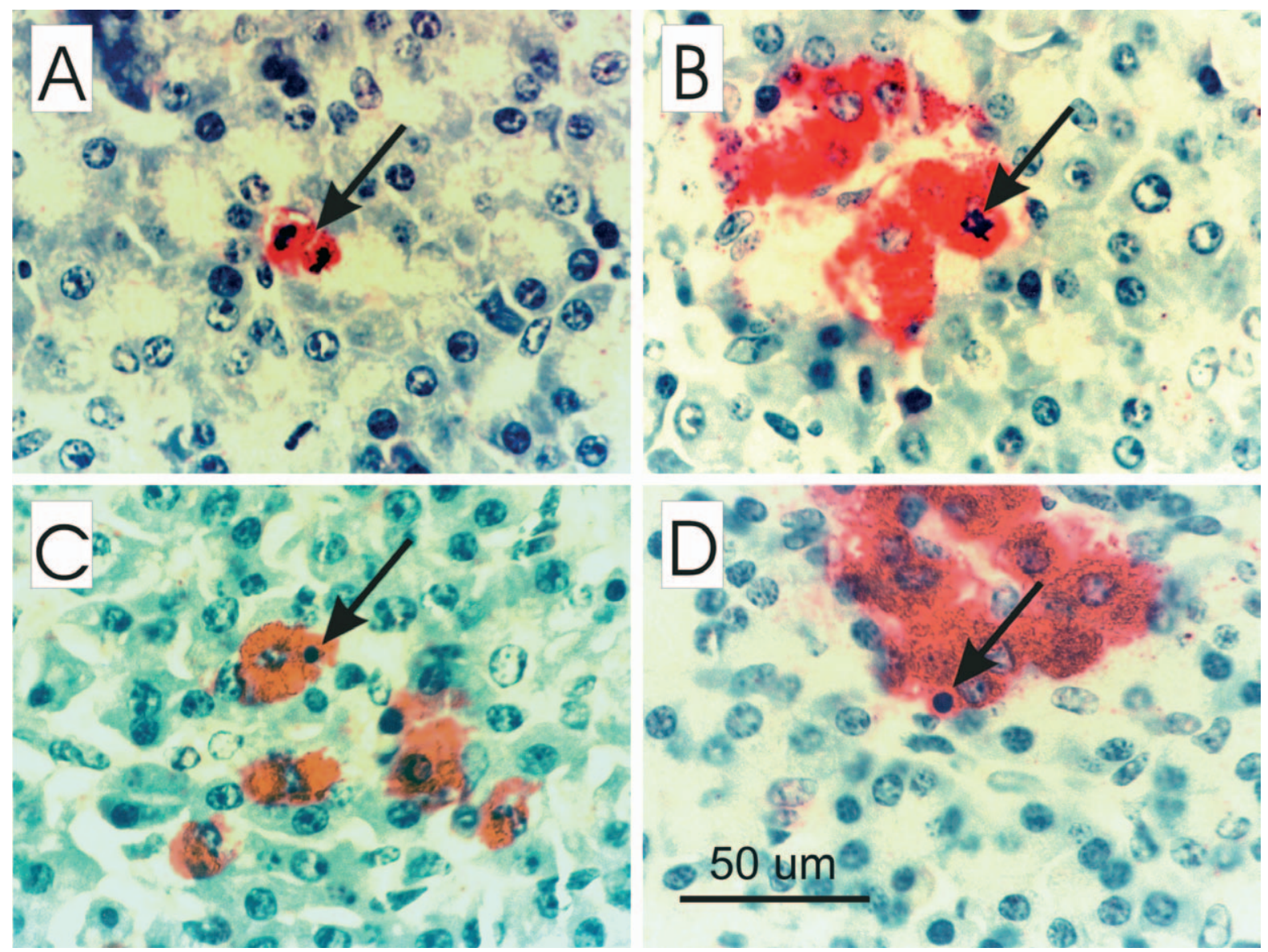

Figure 2 Examples of the morphological appearances of $\beta$-cell nuclei taken into account for $\beta$-cell mitosis and $\beta$-cell apoptosis in the histological sections immunostained for insulin and counterstained with Mayer's haematoxylin. (A) and (B) show examples of mitotic chromatin figures in $\beta$-cell nuclei (arrows), while (C) and (D) show examples of $\beta$-cell apoptosis (small spherical nuclei with condensed chromatin; arrows).

(Fig. 1B). At a final magnification of $\times 583$ we counted how many $\beta$-cell nuclei were sampled by the counting frame in each section and, in addition, how many of these nuclei displayed the morphological characteristics of either mitosis (Fig. 2A-B) or apoptosis (Fig. 2C-D). For each pig an average of $1304 \pm 115$ (means \pm S.E.M.) $\beta$-cell nuclei were counted in the counting frame. The data for $\beta$-cell mitosis and apoptosis are expressed as the ratio of counted $\beta$-cell nuclei that displayed the characteristics of either mitosis or apoptosis.

\section{Volume-weighted mean islet volume}

The volume-weighted mean islet volume was determined as previously described (Skau et al. 2001) by investigating the same sections used for the investigation of $\beta$-cell mitosis and apoptosis. Briefly, at a final magnification of $\times 308$, each section was investigated systematically according to SURS with a point-grid with direction lines attached to the table (Fig. 1C). Each time a point hits an islet, the length of the intersect of a line through the point and oriented according to the direction lines was measured. These sets of intersect lengths were then corrected for magnification and expressed in $\mu \mathrm{m}$. As previously described (Skau et al. 2001), the volume-weighted mean islet volume was then calculated according to:

$\mathrm{v}_{\mathrm{V}}(\mathrm{isl})=\frac{\pi}{3} \times \overline{1_{0}{ }^{3}}$

where $\mathrm{v}_{\mathrm{V}}$ (isl) is the volume-weighted mean islet volume and $l_{0}$ is the length of an intersect through a sampling point in the direction given by the direction lines as described above and illustrated in Fig. 1C. The volume-weighted mean islet volume is the mean islet volume when the islets are sampled (weighted) proportional to their volume. Unless all islets are of identical volume, then the volume-weighted mean islet volume is higher than the number-weighted (ordinary) mean islet volume, as shown by: 
$\mathrm{v}_{\mathrm{v}}=\mathrm{v}_{\mathrm{N}} \times\left(1+\mathrm{CV}_{\mathrm{N}}^{2}\right)$

where $\mathrm{v}_{\mathrm{V}}$ is the volume-weighted mean islet volume, $\mathrm{v}_{\mathrm{N}}$ is the number-weighted (ordinary) mean islet volume, and

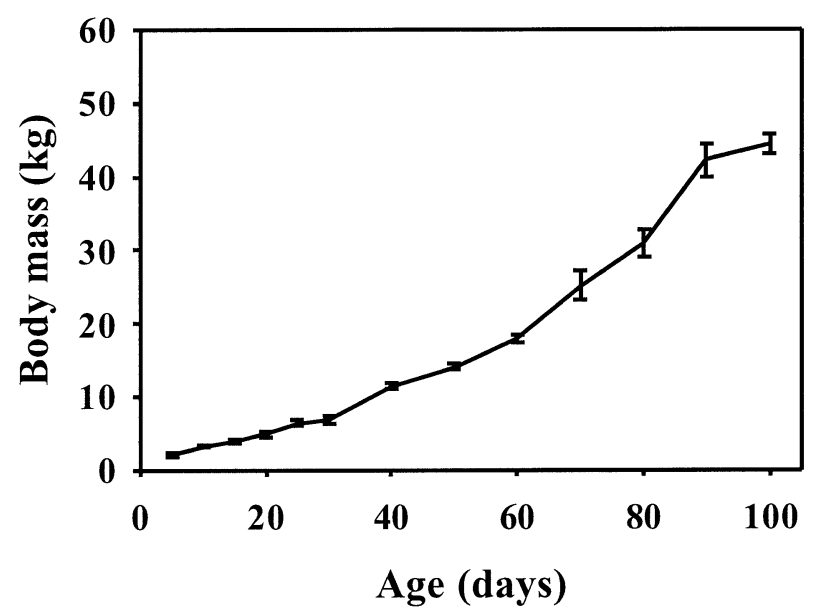

Figure 3 Body mass in the different age groups. Error bars represent the S.E.M.
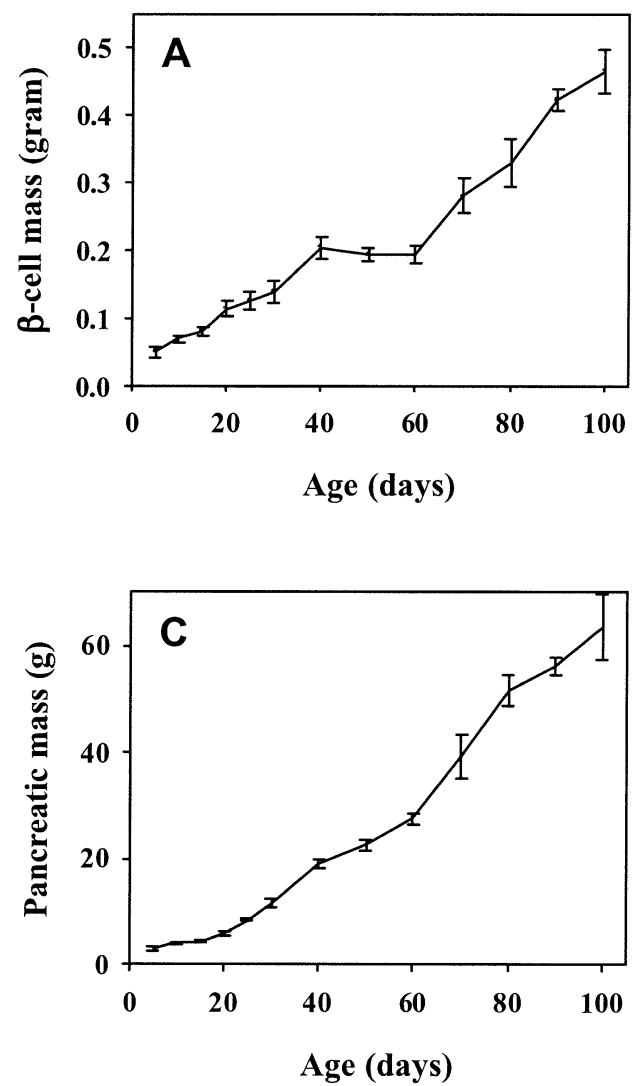

$\mathrm{CV}_{\mathrm{N}}$ is the coefficient of variation between islet volumes in the number-weighted distribution.

\section{Statistics}

Error bars represent the S.E.M. The Pearson productmoment method was used for analysis of correlation. Linear regression analysis was based on the least squares method. The rates of $\beta$-cell mitosis and $\beta$-cell apoptosis over time was evaluated by one-way ANOVA.

\section{Results}

Figure 3 shows body weight as a function of age. This curve is in good agreement with prospective growth curves obtained in commercial pig breeding. The $\beta$-cell mass (Fig. 4A) showed a constant increase from day 5 until day 40 , followed by a plateau until day 60 where it continued to increase into adulthood. The relative $\beta$-cell mass (Fig. 4B) was high in the younger age groups and decreased, most steeply from day 40 until day 60 , to reach a constant (adult) level at day 60 that was maintained for the rest of the period studied. The pancreatic mass
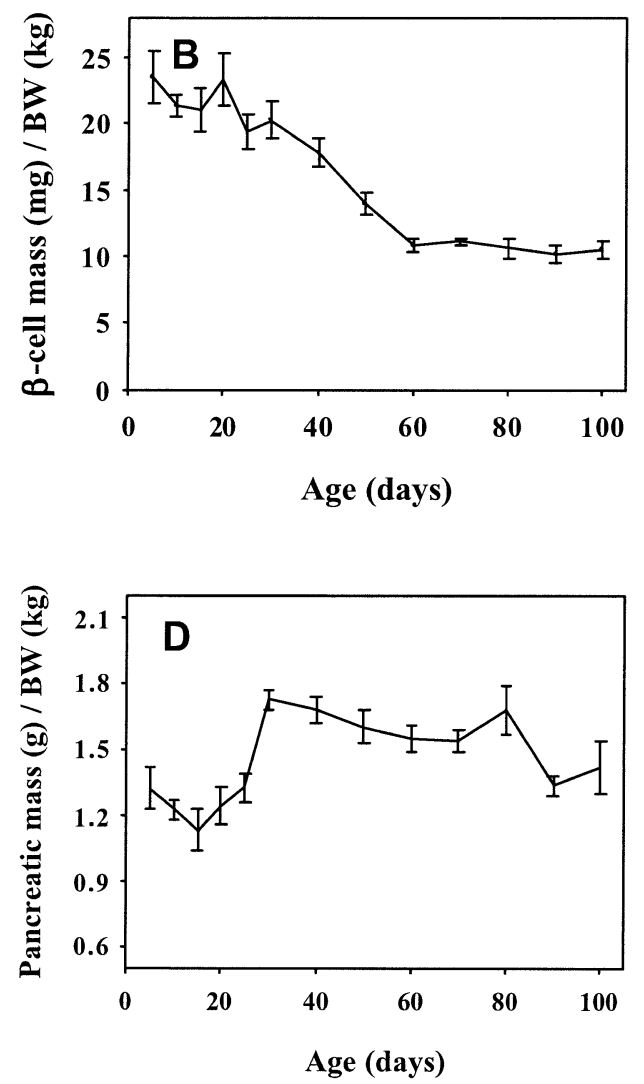

Figure 4 Age versus (A) $\beta$-cell mass, (B) relative $\beta$-cell mass, (C) pancreatic mass and (D) the relative pancreatic mass. Error bars represent the S.E.M. 


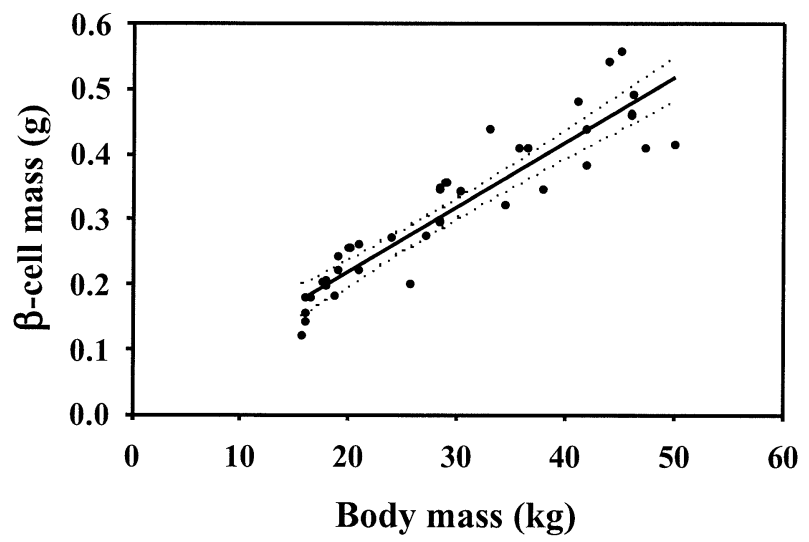

Figure 5 Body mass versus $\beta$-cell mass in pigs of 60 days or older. The solid line is the linear regression line based on the least squares method, the dotted lines show the 95\% confidence interval for the regression line. The parameters for the regression line are given in the text.

(Fig. 4C) increased during the entire age span investigated, while the relative pancreatic mass (Fig. 4D) showed an increase around day 30 followed by a slow decline.

Figure 5 shows the results of the $\beta$-cell mass as a function of age in pigs 60 days of age or older (the period during which the relative $\beta$-cell mass remained at a constant level). There was a significant correlation between the two variables, $r=0.92, P<10^{-14}$. The linear regression line shown in Fig. 5 has the equation:

$\mathrm{M}(\beta)=21.0 \mathrm{mg}+(9.9 \mathrm{mg} / \mathrm{kg} \times \mathrm{BM}(\mathrm{kg}))$

where $\mathrm{M}(\beta)$ is the $\beta$-cell mass and $\mathrm{BM}$ is the body mass. The S.E.M. for the constant was $22.0 \mathrm{mg}$ and $0.71 \mathrm{mg} / \mathrm{kg}$ for the coefficient.

The rates of $\beta$-cell mitosis and apoptosis in the different age groups are shown in Fig. 6. As can be seen, there was a postnatal wave of $\beta$-cell apoptosis (Fig. 6A) that was most pronounced around days 50-60. But, interestingly, Fig. $6 \mathrm{~B}$ shows that the rate of $\beta$-cell mitosis was also relatively high in the period 50-60 days after birth. The difference between the mean values at different ages were, for both parameters, greater than those that would be expected by chance, $P=0.026$ for the rate of apoptosis and $P=0.021$ for the rate of mitosis.

Figure 7 shows typical patterns of the histological appearance of the pancreas in pigs aged 5 and 80 days. The volume-weighted mean islet volume (Fig. 8) increased from a low value at postnatal day 5 to reach a level at approximately day 50 that seemed to be maintained up to day 100 which was the oldest age investigated.

\section{Discussion}

This study revealed striking similarities in the postnatal $\beta$-cell growth in domestic pigs and rats. In both species,
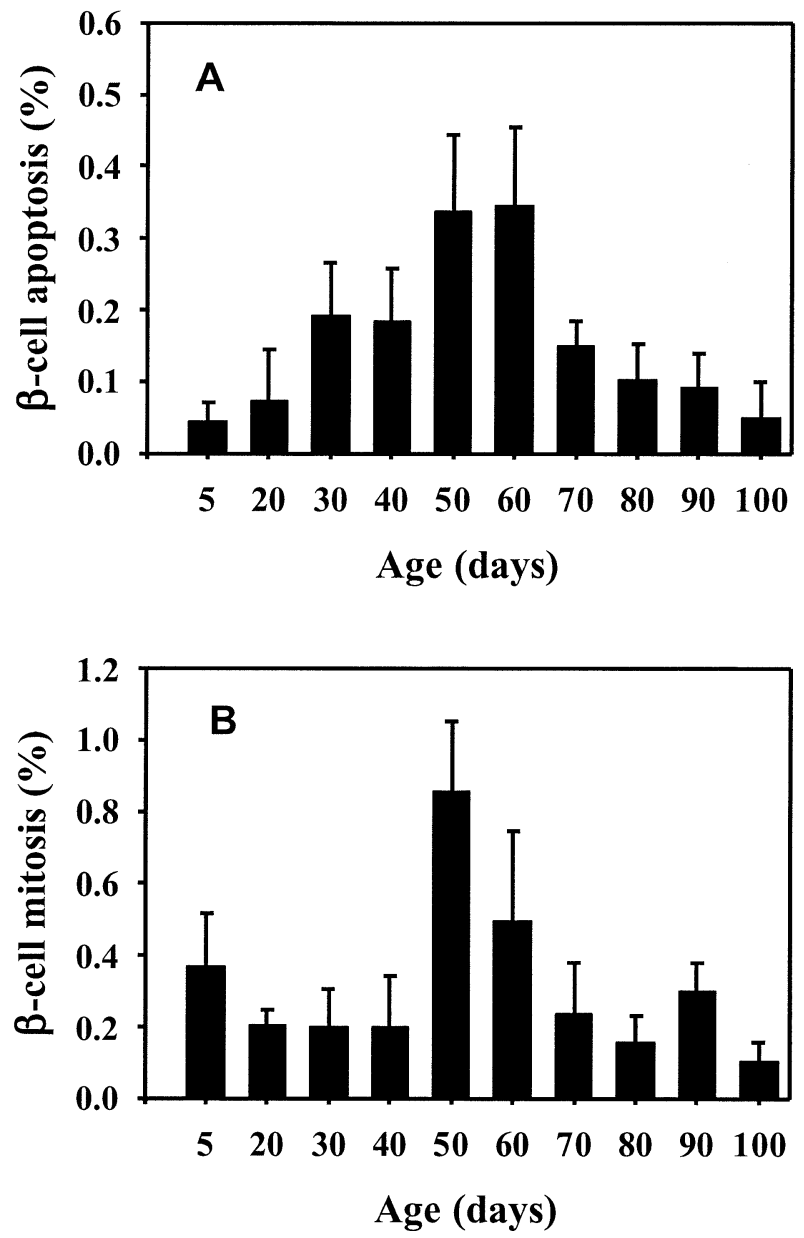

Figure 6 (A) Age versus rate of $\beta$-cell apoptosis and (B) age versus rate of $\beta$-cell mitosis. Error bars represent the S.E.M.

the $\beta$-cell mass increases constantly after birth, reaches a plateau and then increases further into adulthood. The age for the plateau phase differs between the two species since it occurs between day 16 and day 24 (Finegood et al. 1995, Scaglia et al. 1997, Svenstrup et al. 2002) in rats and between day 40 and day 60 in pigs. Even though there is a difference in the time at which the plateau phase occurs, the obvious similarities in the appearance of the $\beta$-cell mass versus age curves in the two species points to a common etiology.

Based on the data from rats reported previously, one could speculate that the etiology of the plateau phase was related to weaning since laboratory rats are usually weaned at postnatal day 21. But since the pigs investigated were weaned at day 28 , this theory is not supported by the results in this study. We previously reported that the $\beta$-cell mass plateau phase coincides in time with the relative $\beta$-cell mass reaching the constant 'adult' level in rats (Svenstrup et al. 2002), and this observation was reproduced in pigs in this study, supporting the view that these 

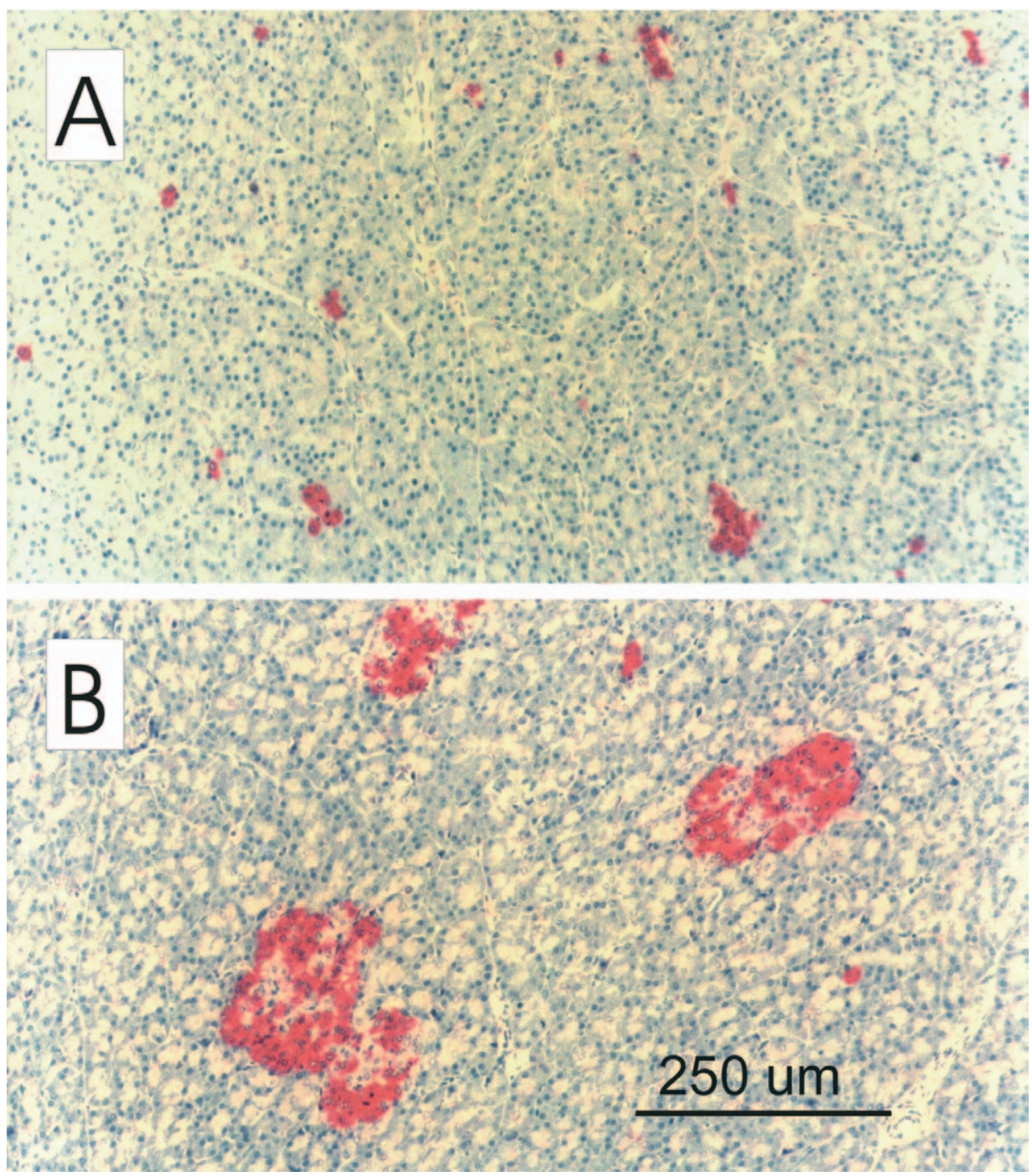

Figure 7 The typical histological appearance of the pancreas in pigs aged (A) 5 and (B) 80 days of age.

two events are causally related. Since the most pronounced decrease in the relative $\beta$-cell mass occurs during the $\beta$-cell mass plateau phase, and especially since the plateau phase ends as the relative $\beta$-cell mass reaches the constant level, the plateau could be interpreted as an adaptive reaction by the $\beta$-cells to the high relative $\beta$-cell mass that ceases when the relative $\beta$-cell mass reaches the constant level as previously suggested (Svenstrup et al. 2002). But this and other theories are limited by the fact that the mechanisms that regulate the $\beta$-cell mass and the relative $\beta$-cell mass are still not understood in detail. It seems evident, however, that the metabolic demand on the $\beta$-cells is important, as shown by the increased $\beta$-cell mass under conditions where there is an increased demand for insulin secretion such as pregnancy (Blondeau et al.
1999), continuous glucose infusion (Bonner-Weir et al. 1989) and obesity in ob/ob mice (Edvell \& Lindstrom 1995), and the decreasing $\beta$-cell mass in the presence of an implanted insulinoma (Blume et al. 1995). But whether the key player is the mean daily insulin secretion, hereditary factors, a complex system of the two, or other factors such as glucagon-like peptide 1 and islet neogenesisassociated protein, is still not known.

The $\beta$-cell mass plateau has been shown to be accompanied by a wave of $\beta$-cell apoptosis in rats (Scaglia et al. 1997). This phenomenon could also be confirmed in this study in pigs, as seen from the high values of $\beta$-cell apoptosis in pigs 50-60 days of age (Fig. 6A). It has previously been shown that two animal models of spontaneous type-1 diabetes, BioBreeding rats and non-obese 


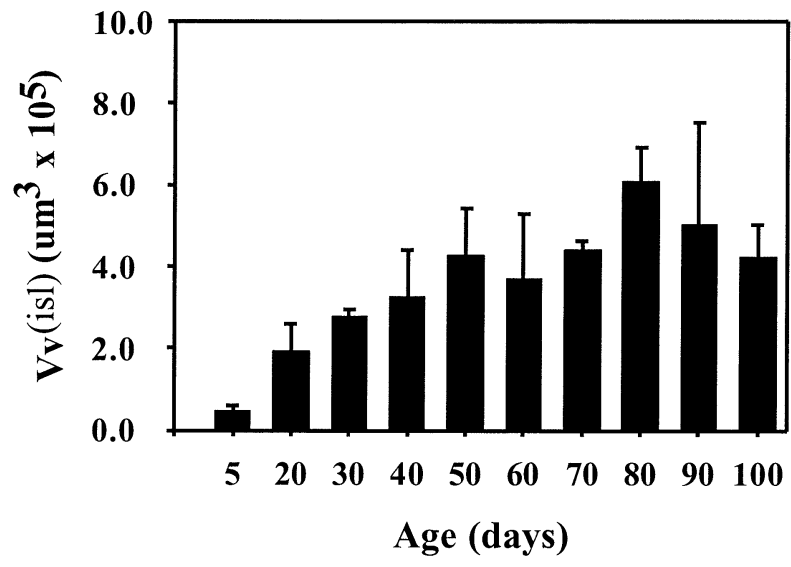

Figure 8 Age versus volume-weighted mean islet volume. Error bars represent the S.E.M.

diabetic mice, display a reduced clearing of apoptotic bodies by macrophages, and this defect may play a role in the $\beta$-cell targeted autoimmunity that leads to diabetes in these models (Trudeau et al. 2000, O'Brien et al. 2002a,b). In this way, the $\beta$-cell mass plateau and the simultaneous increased rate of $\beta$-cell apoptosis may be involved in the pathogenesis of diabetes. However, in contrast to the findings in rats (Scaglia et al. 1997), we also found a wave of $\beta$-cell mitosis at the end of the $\beta$-cell mass plateau phase in pigs. In addition, the volume-weighted mean islet volume increased in the postnatal period but apparently also reached a plateau after approximately 60 days of age in pigs. Together, these findings point to the period around the $\beta$-cell mass plateau phase as representing a period with remodelling of the endocrine pancreas, somewhat in parallel to that which has previously been shown in rats (Scaglia et al. 1997). Which mechanisms drive this remodelling are still not clear, but we suggest that the calibration of the relative $\beta$-cell mass to the level that is maintained into adulthood is a key player, since only this parameter has an obvious direct impact on the overall glucose homeostasis.

The finding of a linear relation between $\beta$-cell mass and body weight in pigs after the end of the plateau phase is also in good agreement with that which has previously been reported in rats (Montanya et al. 2000). The value for the adult steady-state level for the relative $\beta$-cell mass seems to be higher in rats than in pigs, approximately $15 \mathrm{mg} / \mathrm{kg}$ in rats versus $10.5 \mathrm{mg} / \mathrm{kg}$ in pigs. The sudden increase in the relative mass of pancreas around day 30 is probably a consequence of the change in eating behaviour due to weaning at day 28 .

In summary, these data describe the postnatal development of $\beta$-cells in pigs. We have found pronounced similarities between the postnatal growth of the $\beta$-cell mass in pigs and rats such as a plateau phase in the $\beta$ cell mass accompanied by a wave of $\beta$-cell apoptosis, coinciding with the relative $\beta$-cell mass reaching the constant 'adult' level, and the linear correlation between $\beta$-cell mass and body weight thereafter. Given the data from rats and pigs, it would be highly interesting to investigate whether these results could also be reproduced in humans. However, even with access to the pancreases of young humans who have died suddenly, the number of cases needed to give an adequate description of the development in an organ displaying considerable biological variation and, furthermore, prone to fast postmortem degradation, makes such an investigation unlikely. However, non-invasive techniques to measure the $\beta$-cell mass are under development (Moore et al. 2001, Larsen et al. 2003), and these techniques may enable an indirect investigation of human $\beta$-cell mass development in the future. The identical patterns found in two such poorly related mammals as rats and domestic pigs suggests that these patterns are highly conserved and may also occur in the human pancreas.

\section{Acknowledgement}

We thank Helen Nielsen for technical assistance.

\section{Funding}

This work was supported by the Danish Research Council, the Danish Diabetes Association and the H:S Research Foundation.

\section{Refererences}

Blondeau B, Garofano A, Czernichow P \& Breant B 1999 Agedependent inability of the endocrine pancreas to adapt to pregnancy: a long-term consequence of perinatal malnutrition in the rat. Endocrinology 140 4208-4213.

Blume N, Skouv J, Larsson LI, Holst JJ \& Madsen OD 1995 Potent inhibitory effects of transplantable rat glucagonomas and insulinomas on the respective endogenous islet cells are associated with pancreatic apoptosis. Journal of Clinical Investigation 96 2227-2235.

Bonner-Weir S, Deery D, Leahy JL \& Weir GC 1989 Compensatory growth of pancreatic beta-cells in adult rats after short-term glucose infusion. Diabetes 38 49-53.

Edvell A \& Lindstrom P 1995 Development of insulin secretory function in young obese hyperglycemic mice (Umea ob/ob). Metabolism 44 906-913.

Finegood DT, Scaglia L \& Bonner-Weir S 1995 Dynamics of beta-cell mass in the growing rat pancreas. Estimation with a simple mathematical model. Diabetes 44 249-256.

Gundersen HJ \& Jensen EB 1987 The efficiency of systematic sampling in stereology and its prediction. Journal of Microscopy 147 229-263.

Larsen MO, Rolin B, Wilken M, Carr RD \& Gotfredsen CF 2003 Measurements of insulin secretory capacity and glucose tolerance to predict pancreatic $\beta$-cell mass in vivo in the nicotinamide/ streptozotocin Göttingen minipig, a model of moderate insulin deficiency and diabetes. Diabetes 52 118-123. 
Montanya E, Nacher V, Biarnes M \& Soler J 2000 Linear correlation between beta-cell mass and body weight throughout the lifespan in Lewis rats: role of beta-cell hyperplasia and hypertrophy. Diabetes 49 1341-1346.

Moore A, Bonner-Weir S \& Weissleder R 2001 Noninvasive in vivo measurement of beta-cell mass in a mouse model of diabetes. Diabetes $\mathbf{5 0}$ 2231-2236.

O’Brien BA, Fieldus WE, Field CJ \& Finegood DT 2002a Clearance of apoptotic beta-cells is reduced in neonatal autoimmune diabetes-prone rats. Cell Death and Differentiation 9 457-464.

O’Brien BA, Huang Y, Geng X, Dutz JP \& Finegood DT $2002 b$ Phagocytosis of apoptotic cells by macrophages from NOD mice is reduced. Diabetes $\mathbf{5 1}$ 2481-2488.

Scaglia L, Cahill CJ, Finegood DT \& Bonner-Weir S 1997 Apoptosis participates in the remodeling of the endocrine pancreas in the neonatal rat. Endocrinology 138 1736-1741.
Svenstrup K, Skau M, Pakkenberg B, Buschard K \& Bock T 2002 Postnatal development of beta-cells in rats. Proposed explanatory model. Acta Pathologica, Microbiologica, et Immunologica Scandinavica $110372-378$

Skau M, Pakkenberg B, Buschard K \& Bock T 2001 Linear correlation between the total islet mass and the volume-weighted mean islet volume. Diabetes 50 1763-1770.

Trudeau JD, Dutz JP, Arany E, Hill DJ, Fieldus WE \& Finegood DT 2000 Neonatal beta-cell apoptosis: a trigger for autoimmune diabetes? Diabetes 49 1-7.

Received 20 June 2003

Accepted 10 July 2003

Made available online as an

Accepted Preprint 23 July 2003 